\title{
Photodynamic antifungal activity of a superparamagnetic and fluorescent drug carrier system against antibiotic- resistant fungal strains
}

\author{
Sherin Philip - Sunny Kuriakose $\mathbb{E}$
}

Received: 24 April 2021 / Accepted: 23 July 2021 / Published online: 31 July 2021

(C) The Author(s), under exclusive licence to Springer Nature B.V. 2021

\begin{abstract}
Increased antimicrobial resistance demands the development of new antimicrobial agents with high potency. A wide variety of microbial systems are continuously subjected to mutations which ultimately results in antimicrobial resistance. The present study aimed at the fabrication of a nano drug delivery system which simultaneously is superparamagnetic, fluorescent, non-cytotoxic and antifungal. The developed system is an easily targetable and detectable tool owing to its superparamagnetic and fluorescent characteristics respectively. Superparamagnetic iron oxide nanoparticles stabilized by macromolecular starch have been incorporated into a
\end{abstract}

fluorescently modified carrier system to get the final drug delivery system. The finally developed drug carrier system is found to be non-cytotoxic from the in vitro cytotoxicity studies performed against normal rat spleen cells. The photodynamic antifungal capability of the system was the premier concern of investigation of the present study. The antifungal studies were conducted against Histoplasma capsulatum and Trichophyton rubrum by well diffusion method and the results were compared with the activity of the antibiotic, griseofulvin. The minimum inhibitory concentration against each fungal strain was determined using broth dilution method.

Supplementary Information The online version contains supplementary material available at https://doi.org/10.1007/ s10570-021-04107-y.

\section{S. Philip · S. Kuriakose $(\bowtie)$}

Research and Post-Graduate Department of Chemistry, St. Thomas College, Palai 686574, India

e-mail: skresearchgroup16@gmail.com

\section{S. Philip}

e-mail: sherinphilip.m@gmail.com

S. Philip · S. Kuriakose

Mahatma Gandhi University, Kottayam,

Kerala, India 


\section{Graphic abstract}

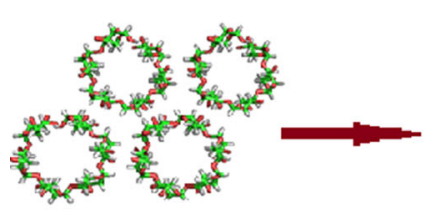

Starch

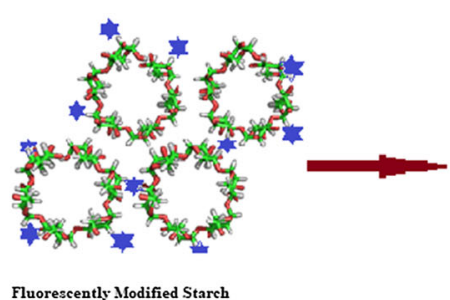

Fluorescently Modified Starch
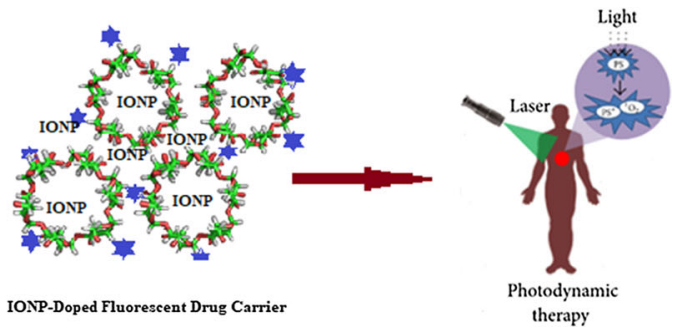

Keywords Iron oxide - Superparamagnetic . Fluorescent · Non-cytotoxic · Photodynamic · Antifungal

\section{Introduction}

Many decades past the discovery of antibiotics, microbial infections have again become a threat (Spellberg and Gilbert 2014). The antibiotic resistance crisis can be attributed to the overuse and misuse of these medications, as well as a lack of new drug development by the pharmaceutical industry due to reduced economic incentives and challenging regulatory requirements (Ventola 2015; Wright 2014; Viswanathan 2002; Read and Woods 2014). Even in 2020, the world is facing a crisis from a pandemic that has frozen the whole life on this planet. We have been shut down for months and living a new routine that this century has never experienced and all these due to a newly discovered corona virus. By this time we are all aware that these ultra-small species are most deadly to people with some other clinical history. Furthermore, more and more reports are coming on the post-covid bacterial and fungal infections caused by various microbial systems such as black fungus or mucor mould causing mucormycosis and yellow fungus causing mucor septicus etc. among the covid patients who survived covid 19 pandemic attack. Any microbe can turn dangerous at any point of time and we should be well equipped with medical tools which are at the same can fight these tiny species. These facts necessitate the need for more research in this field.

The biomedical research is busy with developing highly advanced therapeutic agents for treating fatal diseases. But all these efforts will be in vein if we leave the microbial infections untreated. In this context our study aimed at the development of a superparamagnetic, fluorescent, non-cytotoxic drug carrier which is at the same time antimicrobial.

Like other prominent metallic nanoparticles and their oxides (Ahmad et al. 2020; Shah et al. 2014), iron and iron oxide nanoparticles have already been recognized for their valid and crucial role as antimicrobial agents (Philip and Kuriakose 2017). We have synthesized superparamagnetic iron oxide nanoparticles by means of the macromolecular stabilizing system- starch. Ferrofluids containing encapsulated magnetic iron oxide nanoparticles (IONPs), can be employed for drug delivery (Jain et al. 2005; Chourpa et al. 2005; Dandamudi and Campbell 2007) to specific locations. Exploitation of superparamagnetic magnetization of iron oxide nanoparticles allows for "magnetic dragging" of internal nanoparticles (Blaney 2007)]. If the particle size measures higher than $200 \mathrm{~nm}$, they are easily sequestered by the spleen and eventually removed by the phagocyte cells which results in reduced blood circulation times. Small particles whose size is less than $10 \mathrm{~nm}$ are easily removed by renal activities. In order to obtain a prolonged duration in the blood stream, the optimal size of iron oxide nanoparticles for intravenous injection should range in between 10-100 nm (Laurent et al. 2008). The incorporation of IONPs into starch in the present study aimed at the biocompatibility and superparamagnetism of the newly developed drug carrier.

The superparamagnetic iron oxide nanoparticles were then incorporated into a fluorescently modified starch conjugate. For the fluorescent modification of starch, 1-pyrene butyric acid (PBA) was used. PBA has been used in many labelling (Chen et al. 2011) and sensing (Chen et al. 2001) applications. The 
fluorescent modification enables easy identification of the developed system either in a living or a non-living body. The system was also analysed for its cytotoxic effect on normal rat spleen cells using Trypan blue dye exclusion assay.

The thematic focus of the photochromic/fluorescent modification discussed in this paper is the assessment of the developed system in photodynamic therapy. Photodynamic therapy (PDT) is coming up with new possibilities of treatment in medicine. It uses a photosensitizing drug (photosensitizer, PS) for the treatment of various diseases. When exposed to light with a particular wavelength, these drugs produce free oxygen radicals that can harm the nearby living cells (Kohanski et al. 2007). After excitation, the PS electrons at the singlet excited state will undergo intersystem crossing (ISC) to the triplet state. This triplet state can react with the biomolecules in two different ways (Fig. 1).

Type I reaction involves electron transfer from triplet state PS to an organic substrate within the cells, leading to the production of free radicals. These free radicals interact with oxygen in molecular level and produce reactive oxygen species (ROS) such as superoxide, hydroxyl radicals and hydrogen peroxide that can be harmful to the living cells. In Type II reaction, energy transfer occurs between the excited PS and the ground-state molecular oxygen, producing singlet oxygen that can interact with a large number of molecules in the cell to generate oxidized products (Huang et al. 2012; Foote 1991; Ghorbani et al. 2018).

PDT can be used in various fields of medicine inclusive of antimicrobial therapy, cancer treatment (Wang et al. 2002), ophthalmology and even for the treatment of acne. PDT can be used to effectively destroy microbes like bacteria, fungi and viruses (Rajan et al. 2016). When used for antimicrobial therapy it is more specifically termed as photodynamic antimicrobial chemotherapy (PACT). The finally developed superparamagnetic and fluorescent system was studied for its photodynamic antimicrobial potential against two highly pathogenic fungal strainsHistoplasma capsulatum and Trichophyton rubrum.

Histoplasma capsulatum lives in the environment, particularly in soil that contains large amounts of bird or bat droppings. They are usually found in the river valleys. It can cause histoplasmosis (Wheat et al. 2016) when people inhale these fungal spores from air. All those who breathe in the strain would not get infected. But the problem is serious when it comes with people with a weak immune system or those who are already sick.

Trichophyton rubrum is a dermatophytic fungus that colonizes the upper layers of dead skin, and is the most common cause of athlete's foot (tinea pedis), fungal infection of nail, jock itch, and ringworm (Zaugg et al. 2009). T. rubrum infections are incredibly hard to diagnose, and difficult to differentiate from other dermatophytes since this fungal pathogen is poorly understood. Yet, these infections have been found to be susceptible to photodynamic treatment (Huang 2017).

\section{Experimental}

\section{Materials}

1-pyrene butyric acid (PBA, 97\%), 4-dimethyl aminopyridine (DMAP, 99\%), N, $\mathrm{N}^{\prime}$-dicyclohexyl carbodiimide (DCC, 99\%), dimethyl formamide (DMF, 95\%) and all other solvents were purchased from Sigma-Aldrich. Ferrous sulphate heptahydrate $\left(\mathrm{FeSO}_{4} .7 \mathrm{H}_{2} \mathrm{O}, 99 \%\right)$ was purchased from Nice Chemicals Pvt. Ltd. India. Starch and sodium borohydride $\left(\mathrm{NaBH}_{4}, 98 \%\right)$ were purchased from Merck

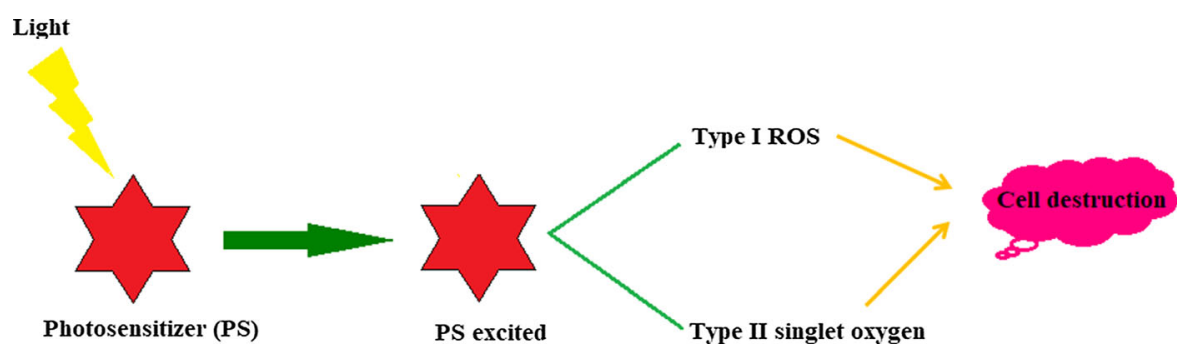

Fig. 1 Mechanism of cell destruction in PDT 
Specialities Pvt. Ltd. Mumbai. All the chemicals and reagents were used without any further purification. Double distilled water was used throughout the experiments.

\section{Instrumentation}

NMR spectra of the pure fluoroprobe and its modified analogues were recorded on a Bruker Avance NMR spectrometer $\left({ }^{1} \mathrm{H}, 500 \mathrm{MHz}\right)$. Powder XRD studies were conducted using Rigaku Miniflex 600 XRD instrument operating at $1.54 \AA$ with a $\mathrm{CuK} \alpha$ source. A Jeol/JEM 2100 high resolution transmission electron microscope (HRTEM) operating at $200 \mathrm{kV}$ was used to record the TEM images. The magnetic properties were analysed using a Lake Shore Cryotronics vibrating sample magnetometer (VSM). The UV/visible absorption spectrum was recorded on a Shimadzu UV/visible spectrophotometer in the range 190-1100 nm. Horiba Flouoromax-4- spectrofluorometer was used for fluorescence measurement.

Synthesis of starch stabilized, superparamagnetic iron oxide nanoparticles (IONP)

$\mathrm{Fe}^{2+}$ ions of the precursor $\mathrm{FeSO}_{4} \cdot 7 \mathrm{H}_{2} \mathrm{O}$ were encapsulated into the macromolecular scaffolds of soluble starch by magnetic stirring. The encapsulated ferrous ions were then reduced to $\mathrm{Fe}(0)$ by sodium borohydride addition. The zero-valent iron was then air oxidized to $\mathrm{Fe}_{2} \mathrm{O}_{3}$. The detailed synthetic procedure is reported elsewhere (Philip and Kuriakose 2020).

Fluorescent modification of starch with 1-pyrene butyric acid by Steglich esterification (Neises and Steglich 1978)

To fluorescently modify macromolecular starch, the fluoroprobe 1-pyrene butyric acid (PBA) was used in molar excess as the study did not involve any quantitative estimation of the hydroxyl groups of starch. Starch, soluble $(0.1 \mathrm{~g})$ and pyrene butyric acid $(0.5 \mathrm{~g})$ in $10 \mathrm{ml}$ DMF each were mixed together followed by addition of $10 \mathrm{ml}$ DCC $(0.5 \mathrm{~g})$ in DMF. A catalytic amount of DMAP (200 mg) was added and the mixture was stirred at room temperature for $2 \mathrm{~h}$ and then at $80{ }^{\circ} \mathrm{C}$ for $6 \mathrm{~h}$ under nitrogen flushing. The mixture was then cooled to room temperature and then freezed at $-25^{\circ} \mathrm{C}$ and filtered to remove the reaction byproduct dicyclohexyl urea (DCU) and all the unreacted molecules. The solvent was evaporated using a rotary flash evaporator and the product was dried. The dried fluorescent starch (FS) was then purified by column chromatography using 10:3 hexane-ethyl acetate mixture.

NMR spectra were recorded for pure PBA (Online Resource 1 Fig. S1) and the developed fluorescent starch-PBA aggregate (FS) (Online Resource 1 Fig. S2).

${ }^{1} \mathrm{H}$ NMR (PBA) $\left(500 \mathrm{MHz}, \mathrm{CDCl}_{3}\right): \delta 9.16 \mathrm{ppm}$ $(1 \mathrm{H}, \mathrm{s},-\mathrm{COOH}$ proton 'a'), $\delta$ 7.8-8.3 ppm (aromatic protons of pyrene), $\delta 3.44 \mathrm{ppm}(2 \mathrm{H}$, t, aliphatic protons 'b'), $\delta 2.53 \mathrm{ppm}(2 \mathrm{H}$, t, aliphatic protons 'd'), $\delta 2.25 \mathrm{ppm}(2 \mathrm{H}, \mathrm{m}$, aliphatic protons 'c') and $\delta$ $7.3 \mathrm{ppm}\left(\mathrm{CDCl}_{3}\right.$ solvent $)$.

${ }^{1} \mathrm{H}$ NMR (FS) (500 MHz, $\left.\mathrm{CDCl}_{3}\right): \delta 7.86-8.3 \mathrm{ppm}$ (aromatic protons of pyrene), $\delta 3.41 \mathrm{ppm}(2 \mathrm{H}, \mathrm{t}$, aliphatic protons 'b'), $\delta 2.88 \mathrm{ppm}(1 \mathrm{H}, \mathrm{s}, \mathrm{COOR}-\mathrm{CH}-$ proton ester), $\delta 2.4 \mathrm{ppm}(2 \mathrm{H}$, t, aliphatic protons 'd'), $\delta 2.23 \mathrm{ppm}(2 \mathrm{H}, \mathrm{m}$, aliphatic protons 'c') and $\delta$ $7.26 \mathrm{ppm}\left(\mathrm{CDCl}_{3}\right.$ solvent $)$.

The peak corresponding to - $\mathrm{COOH}$ proton around $9.16 \mathrm{ppm}$ in PBA was absent in FS indicating the complete esterification of all the carboxylic groups of PBA with hydroxyl groups of starch. The formation of ester is further confirmed by a sharp peak at $2.88 \mathrm{ppm}$ corresponding to $\alpha$-hydrogens in starch bonded to COOR group.

Development of the drug carrier (DC) system by doping superparamagnetic IONP into fluorescent starch-PBA conjugates (FS)

Fluorescently modified starch (FS) $(0.010 \mathrm{~g}, 10 \mathrm{ml})$ and superparamagnetic IONP $(0.010 \mathrm{~g}, 10 \mathrm{ml})$ dispersions in DMF were mixed thoroughly and magnetically stirred for $1 \mathrm{~h}$ at $80{ }^{\circ} \mathrm{C}$ and further for $4 \mathrm{~h}$ at $25^{\circ} \mathrm{C}$ under nitrogen flushing. The solvent was evaporated using a rotary flash evaporator and the product was dried at room temperature in vacuum. The resultant drug carrier system, DC was purified using column chromatography with $8: 2(\mathrm{v} / \mathrm{v})$ acetonitrilemethanol solvent system on a 100-200 mesh silica (Merck India Pvt. Ltd.) filled $2 \times 20 \mathrm{~cm}$ adsorption column.

The synthetic procedures described for IONP, FS and DC are summarized respectively in the following Eqs. (1), (2) and (3) given below. 
$\mathrm{Fe}_{2} \mathrm{SO}_{4} \cdot 7 \mathrm{H}_{2} \mathrm{O}+\mathrm{Starch} \underset{200^{\circ} \mathrm{C}}{\stackrel{\mathrm{NaBH}_{4}, \mathrm{O}_{2}}{\longrightarrow}}$

IONP (Superparamagnetic Iron Oxide Nanoparticle)

1 - Pyrene Butyric Acid (PBA) + Starch

$\rightarrow$ FS (Fluorescent Starch)

$$
\text { IONP (from (1)) + FS (from (2)) }
$$$$
\rightarrow \text { DC (Drug Carrier) }
$$

In vitro cytotoxicity analysis against normal rat spleen cells

The test compound was studied for short term in vitro cytotoxicity using rat spleen cells. Rat was sacrificed using carbondioxide anaesthesia and the spleen tissue was dissected out. It was then smashed to single cell suspension in RPMI (Roswell Park Memorial Institute) complete medium containing antibiotics and filtered using mesh cloth. The collected cells were washed thrice and suspended in known volume of RPMI complete medium containing antibiotics and counted. Viable cell suspension $\left(1 \times 10^{6}\right.$ cells in $0.1 \mathrm{ml}$ ) was added to tubes containing various concentrations of the test compound and the volume was made upto $1 \mathrm{ml}$ using RPMI media. Control tubes contained only cell suspension (without additives). These tubes were mixed with $0.1 \mathrm{ml} 1 \%$ trypan blue and kept for 2-3 min and loaded on a haemocytometer. Dead cells take up the blue colour of trypan blue while live cells do not take up the dye. The number of stained and unstained cells was counted separately using Eq. (4) given below.

$$
\% \text { cytoxicity }=\frac{\text { Numberofdeadcells }}{\begin{array}{l}
\text { Numberoflivecells }+ \text { Numberofdeadcells } \\
\times 100
\end{array}}
$$

Agar well diffusion method for antifungal studies

Petriplates containing $20 \mathrm{ml}$ Mueller Hinton medium were seeded with $24 \mathrm{~h}$ culture of fungal strains. Wells of diameter 6-8 $\mathrm{mm}$ were cut aseptically with a sterile cork borer into which $20 \mu \mathrm{l}$ of the sample dispersion of desired concentration was introduced. The plates were then incubated at $37{ }^{\circ} \mathrm{C}$ for $24 \mathrm{~h}$. The antifungal activity was assayed by measuring the diameter of the inhibition zone formed around the well.

Minimum inhibitory concentration (MIC): broth microdilution method

Minimum inhibitory concentration (MIC) of an antimicrobial agent is defined as its lowest concentration that can result in visible inhibition of the microbial growth. MIC also establishes the level of microbial resistance to an antimicrobial agent. The minimum inhibitory concentration (MIC) was determined using broth micro dilution method. $50 \mu \mathrm{l}$ of sample solution in twofold dilutions $(2.5 \mu \mathrm{g} / \mathrm{ml}, 5 \mu \mathrm{g} /$ $\mathrm{ml}, 10 \mu \mathrm{g} / \mathrm{ml}, 20 \mu \mathrm{g} / \mathrm{ml}$ and $40 \mu \mathrm{g} / \mathrm{ml}$ ) were prepared in broth medium using a 96-well microtitration plate. Each well is then inoculated with $50 \mu \mathrm{l}$ of the microbial inoculum prepared in the same growth medium after dilution to $0.5 \mathrm{McF}$ arland scale. After well-mixing, the inoculated wells were incubated for $18 \mathrm{~h}$ at $37^{\circ} \mathrm{C}$. MIC was taken as the lowest concentration that causes a visible inhibition of fungal growth which is indicated by absence of turbidity on addition of the antimicrobial solution. CLSI has standardized the broth dilution protocol for fungi.

\section{Results and discussions}

The superparamagnetic IONP and the IONP encapsulated drug carrier systems were characterized by different analytical techniques and then undergone for PDT studies.

\section{XRD studies}

Powder XRD was performed on the superparamagnetic IONP and the final drug carrier system, DC into which IONP has been doped. Both the samples showed distinct diffraction pattern (Fig. 2) characteristic of $\alpha-\mathrm{Fe}_{2} \mathrm{O}_{3}$ nanoparticles (JCPDS No. 33-0664). No other phases of iron oxide were present as impurities. The retention of well-defined peaks of crystalline $\alpha-\mathrm{Fe}_{2} \mathrm{O}_{3}$ nanoparticles even after doping is a sign of enhanced stability of the nanoparticles within the macromolecular scaffolds of the stabilizing system-starch. 

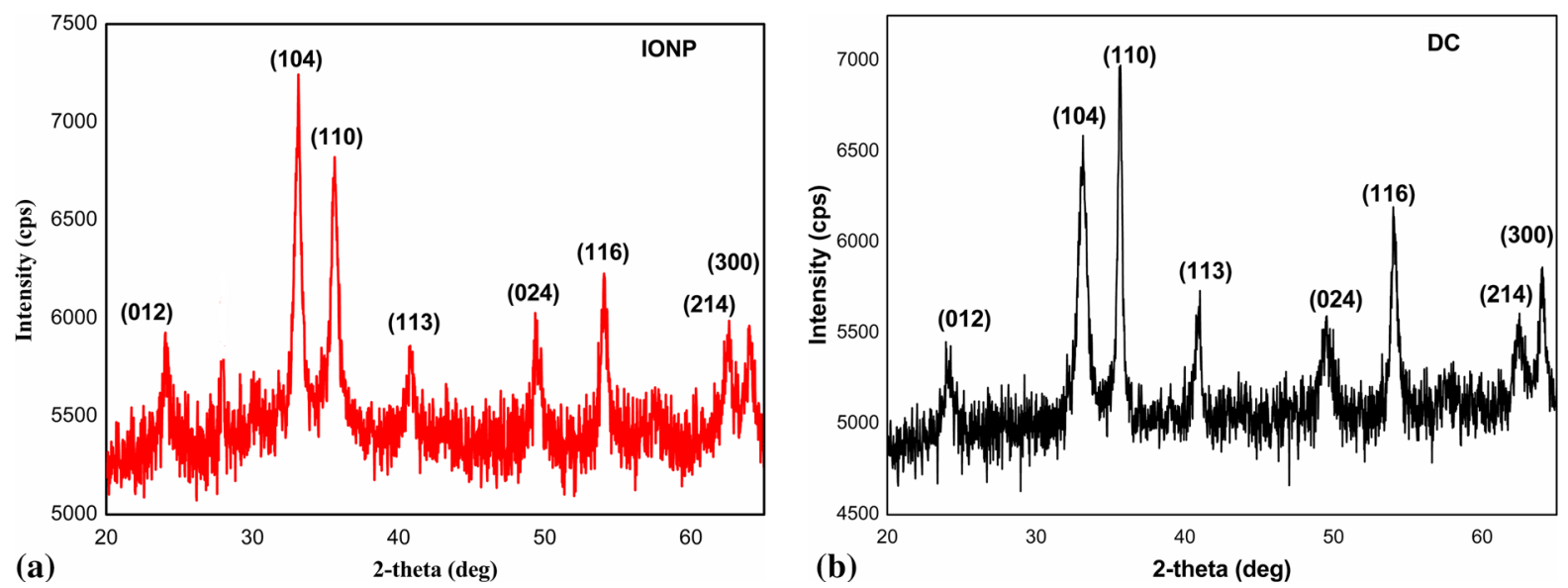

Fig. 2 XRD pattern of a IONP and $\mathbf{b}$ IONP incorporated drug carrier DC

Debye Scherrer equation, $d=K \lambda / \beta \cos \Theta$. was used to calculate the particle size. IONPs before doping were found to be in the particle size range of 12-17 $\mathrm{nm}$. The particle size was calculated to be in the range of 12-24 nm for IONPs after being doped to get the drug carrier. This mild but negligible increase in particle size may be due to possibility for slight aggregation.

\section{HRTEM analysis}

High resolution TEM images were recorded for the samples IONP and DC (Fig. 3). IONPs before doping (Fig. 3a) exhibit distinct hexagonal iron oxide nanoparticles which again confirms the characteristics of $\alpha-\mathrm{Fe}_{2} \mathrm{O}_{3}$. The particles more or less fall around $20 \mathrm{~nm}$ in particle size which is almost in agreement with the XRD results.

Figure $3 \mathrm{~b}$ reveals the microscopic morphology of the finally developed drug carrier (DC), which has been synthesized by incorporationg superparamagnetic IONPs into the fluorescent starch (FS). The image reveals particles those exhibit a slight degree of aggregation which resulted in slight particle size increase as predicted by XRD. Apart from the mild degree of aggregation, the successful incorporation of IONPs into the drug delivery system is confirmed by XRD and HRTEM analyses.

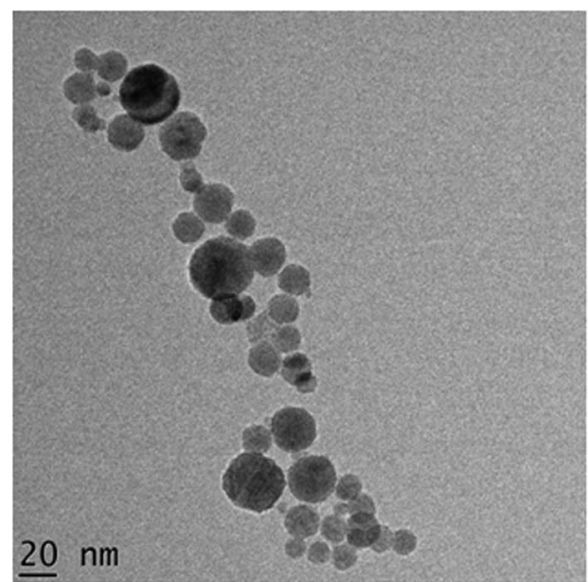

(a)

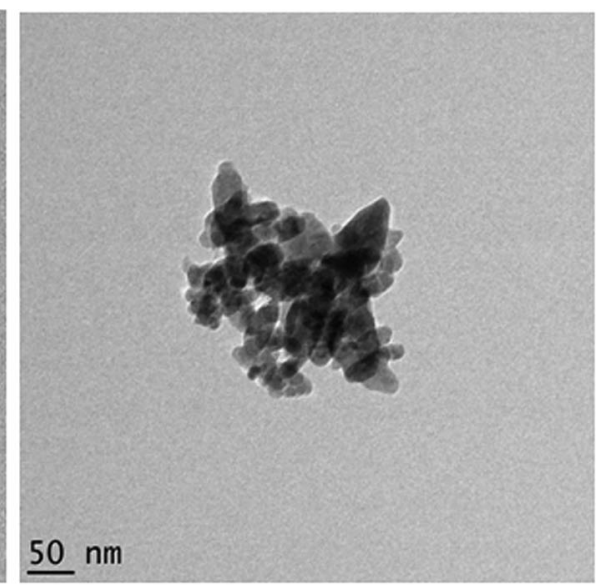

(b)

Fig. 3 HRTEM images of nanoparticles in a IONP and b IONP incorporated drug carrier Drug carrier (DC) 
Magnetic properties

The magnetic properties of the systems-IONP and DC were studied using a vibrating sample magnetometer (VSM). The measurements were done at room temperature (Fig. 4).

The two samples exhibited $\mathrm{M}-\mathrm{H}$ curves without the evidence of any hysteresis which is an indication of their superparamagnetic behaviour. The coercivity of the sample was observed to be increased to $69.860 \mathrm{G}$ from $20.371 \mathrm{G}$ upon incorporation into the fluorescent system which may be due to the aggregation of particles. However the retention of superparamagnetic behaviour of IONPs even after doping into the fluorescently modified macromolecular scaffolds is promising while their drug carrier potential is to be considered. The superparamagnetic particles can easily be targeted to the site of action by an external magnetic field. This précised targeting can, of course, reduce the complications of a treatment protocol.

UV/visible absorption and Photoluminescence spectra

The UV/visible absorption spectrum of the IONP incorporated drug carrier system (DC) was recorded in DMF in the range 190-1100 nm (Fig. 5a). Three characteristic absorption peaks of pyrenyl moiety were observed above $300 \mathrm{~nm}$. Photoluminescence (PL) emission spectrum of DC was recorded at an excitation wavelength of $295 \mathrm{~nm}$ (Fig. 5b). The excitation wavelength was fixed at $295 \mathrm{~nm}$ owing to the well characterized absorptions of pyrenyl species above $300 \mathrm{~nm}$.

The first three intense peaks-378 nm, $398 \mathrm{~nm}$ and $420 \mathrm{~nm}$ are characteristic emissions of pyrene monomers from PBA used for the fluorescent modification of starch and the weak peak broad one around $445 \mathrm{~nm}$ indicates a negligible amount of pyrene as dimers in the excited state (excimers) (Philip and Kuriakose 2019). The spectrum confirms the successful esterification between PBA and starch. The emission of the drug carrier solution in UV light is given in the inset of Fig. 5b, which clearly reveals the fluorescent nature of the newly developed drug delivery system.

In vitro cytotoxicity analysis of the superparamagnetic fluorescent drug carrier (DC)

The short term in vitro cytotoxicity analysis was conducted for the finally developed drug carrier, DC at five different concentrations in DMF $(10 \mu \mathrm{g} / \mathrm{ml}$, $20 \mu \mathrm{g} / \mathrm{ml}, \quad 50 \mu \mathrm{g} / \mathrm{ml}, \quad 100 \mu \mathrm{g} / \mathrm{ml}$ and $200 \mu \mathrm{g} / \mathrm{ml})$ against normal rat spleen cells and the results are noted in Table 1. The graphical representation is given in Fig. 6. Linear trendline is plotted which can be used to calculate the $\mathrm{IC}_{50}$ (half maximal inhibitory concentration) value by regression analysis. $\mathrm{IC}_{50}$ is a measure of the potency of a substance or drug in inhibiting a specific biological or biochemical function. It is the concentration of a drug that is required for $50 \%$ inhibition of a biological process or component in vitro.

It is clear from Table 1 that our system exhibited only the least cell death of $4 \%$ even at the maximum concentration of $200 \mu \mathrm{g} / \mathrm{ml}$. It is worth to mention that even the control cell death was $4 \%$. The results have proven the non-cytotoxicity of the system.
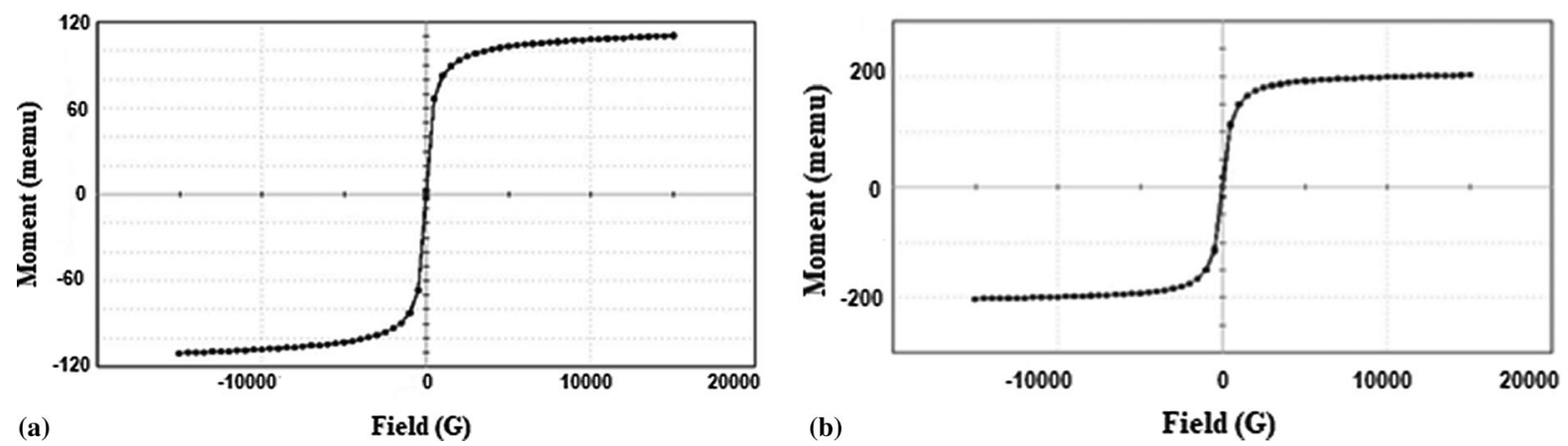

Fig. 4 M-H curve of a IONP and b IONP incorporated drug carrier (DC) 

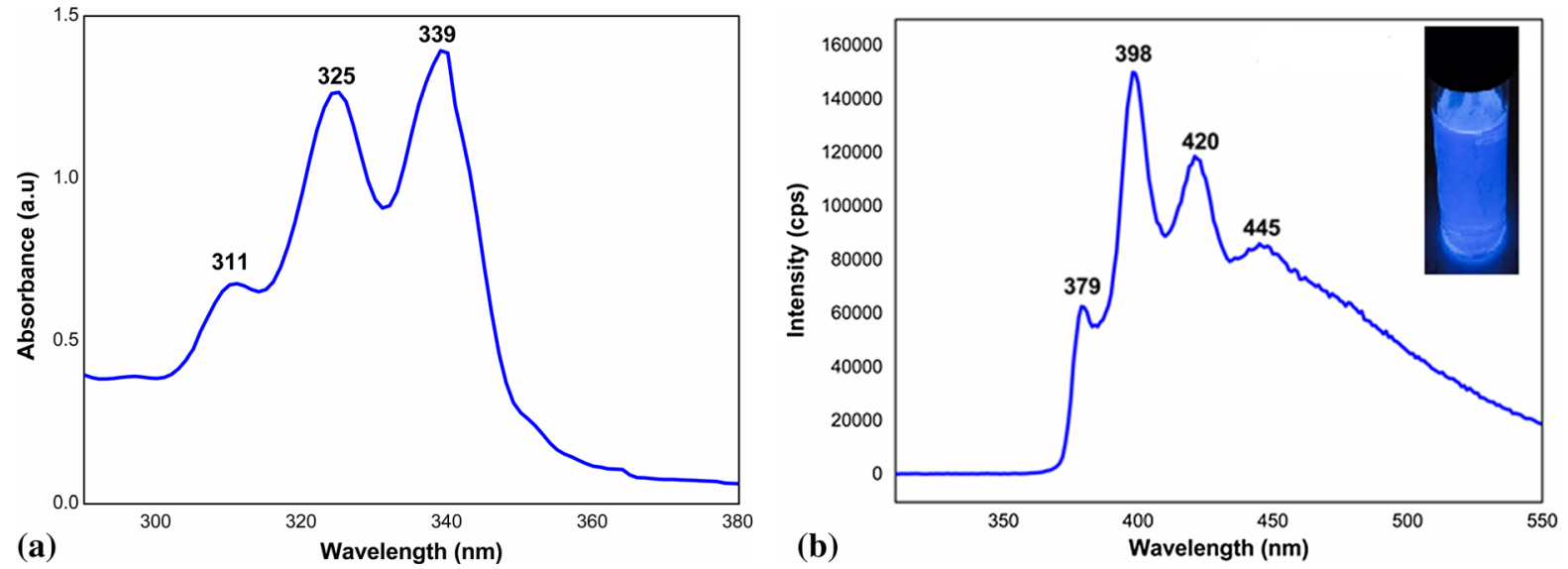

Fig. 5 a UV/visible absorption and b Photoluminescence spectra of the drug carrier (DC)

Table 1 In vitro cytotoxicity analysis of DC against normal rat spleen cells

\begin{tabular}{llllllll}
\hline Cell line & \multicolumn{2}{l}{ Percentage cell death at } & & Control (cell death) & IC \\
\cline { 2 - 6 } & $10 \mu \mathrm{g} / \mathrm{ml}$ & $20 \mu \mathrm{g} / \mathrm{ml}$ & $50 \mu \mathrm{g} / \mathrm{ml}$ & $100 \mu \mathrm{g} / \mathrm{ml}$ & $200 \mu \mathrm{g} / \mathrm{ml}$ & \\
\hline Normal & 0 & 0 & 0 & 2 & 4 & $4 \%$ & 2.30 \\
\hline
\end{tabular}

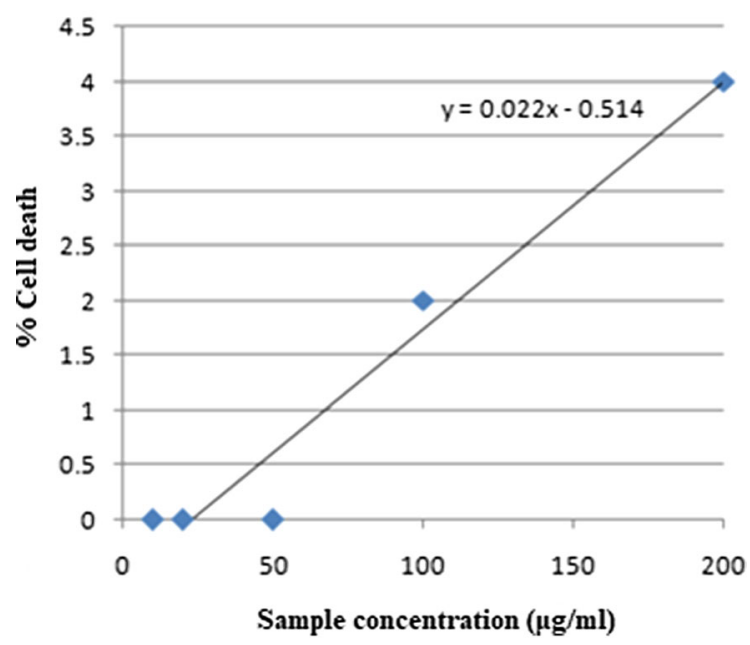

Fig. 6 Linear regression analysis for the cytotoxicity analysis of DC against normal rat spleen cells
Photodynamic antifungal activity and MIC determination of the newly developed superparamagnetic, fluorescent and non-cytotoxic drug carrier system

Antifungal activity of pure fluoroprobe (PBA), functionally modified starch (FS) and the final drug carrier (DC) against $H$. capsulatum and T. Rubrum was studied by well diffusion method. PDT (photodynamic therapy) studies of the drug carrier were conducted after irradiating DC for $2 \mathrm{~h}$ using a Newport Xenon arc lamp of $300 \mathrm{~W}$. The time for irradiation was optimized to be $2 \mathrm{~h}$ as there was no observed increase in the antimicrobial activity after $2 \mathrm{~h}$. The sample after irradiation is denoted as DC*. The activities of the samples were compared with the antibiotic, griseofulvin. Water is the negative control. The results are shown in Fig. 7 and zones of inhibition are noted in Table 2.

Minimum inhibitory concentration (MIC) against each strain was determined for the irradiated sample (DC*) using micro broth dilution method. MIC is the minimum concentration of an antimicrobial that visibly inhibits the growth of the microbe. The 


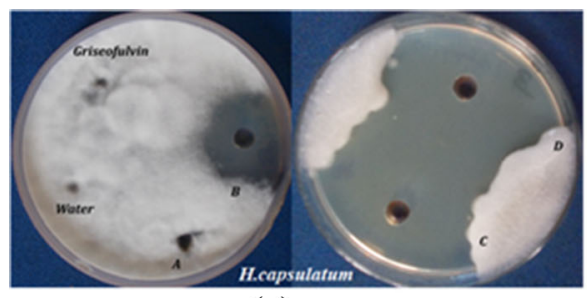

(a)

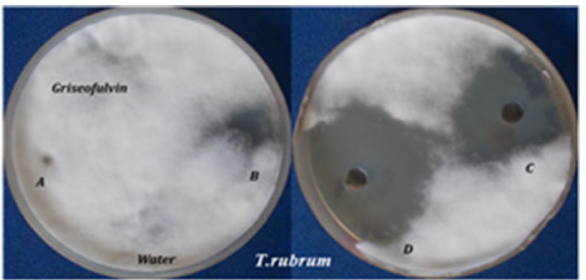

(b)

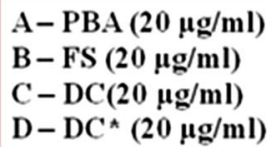

Fig. 7 Photodynamic antifungal activity against a H. capsulatum and b T. rubrum ('*’: irradiated sample)

Table 2 Antifungal zones of inhibition in PACT

\begin{tabular}{llllll}
\hline Fungal strain/sample & \multicolumn{4}{l}{ Zone of inhibition \pm standard deviation $(\mathrm{mm})$} \\
\cline { 2 - 6 } & PBA & FS & DC & DC* & Griseofulvin (antibiotic) \\
\hline H. capsulatum & 0 & $27.00 \pm 1.67$ & $44.00 \pm 0.89$ & $54.17 \pm 1.72^{\mathrm{a}}$ & 0 \\
T. rubrum & 0 & $20.17 \pm 0.98$ & $45.00 \pm 1.55$ & $54.33 \pm 0.82^{\mathrm{a}}$ & 0 \\
$\mathrm{P} \leq 0.05 \mathrm{~F}=435.949$ & & & & & \\
\hline
\end{tabular}

‘*'Irradiated sample. The significance level 'a' predicted by DMRT says that the two results are statistically equivalent

experiments were performed at five different concentrations-2.5 $\mu \mathrm{g} / \mathrm{ml}, 5 \mu \mathrm{g} / \mathrm{ml}, 10 \mu \mathrm{g} / \mathrm{ml}, 20 \mu \mathrm{g} / \mathrm{ml}$ and $40 \mu \mathrm{g} / \mathrm{ml}$ to determine the MIC.

All the measurements were done in six replicates and one-way ANOVA was carried out on all the results. Duncan's multiple range test (DMRT) is used as the post-hoc test at a significance level of $\mathrm{p} \leq 0.05$ using SPSS 16.0 software in the present statistics.

The fluoroprobe PBA was found to be inactive against the two strains in the study. FS and DC exhibited considerable activity against the two microbes and their zones of inhibition were almost similar against each strain. But the point of interest is the activity boost observed upon irradiation of the sample. The irradiated sample, DC* have marked an increase in zone diameter of about $10 \mathrm{~mm}$ against each strain. The above mentioned result is an indication of the success of our presently modified drug system in photodynamic therapy (PDT) or more specifically photodynamic antimicrobial chemotherapy (PACT). The irradiated system showed remarked activity against T.rubrum $(54.33 \pm 0.82 \mathrm{~mm})$ and H.capsulatum $(54.17 \pm 1.72 \mathrm{~mm})$. Another important finding is that these strains found highly susceptible in our PDT studies are found to be resistant to the currently used antibiotic, griseofulvin. Griseofulvin had no zone of inhibition against any of the two strains.

Membrane disruption and cell cycle arrest are the most proposed mechanisms of the antifungal activity of the antimicrobials involving nanoparticles (Kumari et al. 2019; Kim et al. 2009). Reactive oxygen species (ROS) dependent fungal cell death can also be a reason (Das et al. 2016). ROS could be the predominant mechanism of fungal inhibition in PDT. Highly reactive species generated from excited PS may harm the microbial cells by type-I or type-II inhibition as detailed in introduction.

The graphical analysis is given in Fig. 8 in which the increase in antifungal activity upon irradiation is clearly established. MIC values for each strain is determined and noted in Table 3. MIC value determined for each strain in PDT is $2.5 \mu \mathrm{g} / \mathrm{ml}$. The 


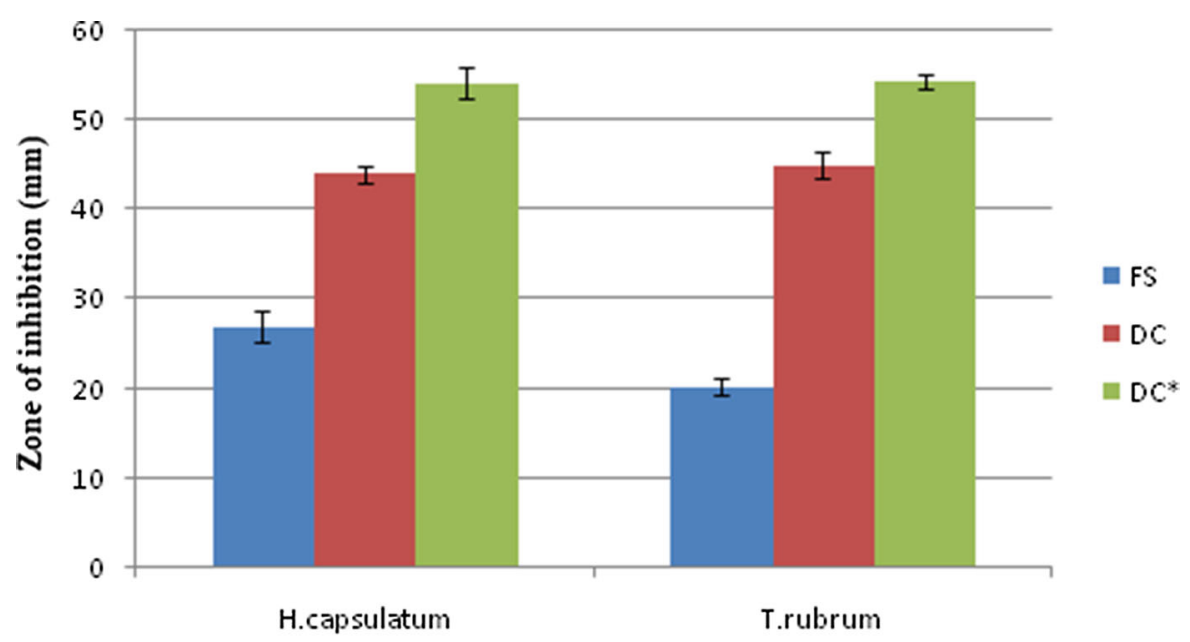

Bacterial strain

Fig. 8 Graphical plot of photodynamic antifungal activity $20 \mu \mathrm{g} / \mathrm{ml}$

Table 3 Antifungal zones of inhibition and MIC values of DC* in PACT (Photodynamic antimicrobial chemotherapy)

\begin{tabular}{|c|c|c|c|c|c|c|c|}
\hline \multirow[t]{2}{*}{ Fungal strain } & \multirow{2}{*}{$\begin{array}{l}\text { Zone of inhibition } \pm \text { standard } \\
\text { deviation }(\mathrm{mm})\end{array}$} & \multicolumn{5}{|c|}{ MIC determination } & \multirow[t]{2}{*}{$\mathrm{MIC}(\mu \mathrm{g} / \mathrm{ml})$} \\
\hline & & $2.5 \mu \mathrm{g} / \mathrm{ml}$ & $5 \mu \mathrm{g} / \mathrm{ml}$ & $10 \mu \mathrm{g} / \mathrm{ml}$ & $20 \mu \mathrm{g} / \mathrm{ml}$ & $40 \mu \mathrm{g} / \mathrm{ml}$ & \\
\hline H. capsulatum & $54.17 \pm 1.72$ & - & - & - & - & - & 2.5 \\
\hline T. rubrum & $54.33 \pm 0.82$ & - & - & - & - & - & 2.5 \\
\hline
\end{tabular}

'-' sign against each concentration in table 3 denotes the inhibition of microbial growth at the particular concentration.

\section{Conclusions}

The instant biomimicing capacity of infectious microbes leads to withdrawal of many novel antibiotics within a short period. Increased prevalence in antimicrobial resistance to traditional antibiotics necessitates the need for development of novel and much more improved antimicrobial agents. The present paper discussed the development of a novel antimicrobial agent with potent photodynamic activity. The system besides its antifungal property possesses superparamagnetic and fluorescent characteristics with absolutely non-cytotoxic traits. The use of starch for the stabilization of nanoparticles as well as for the construction of the drug carrier renders the system more biocompatible. The drug carrier system developed can be precisely targeted due to its superparamagnetism and easily detected owing to its fluorescence. The presently developed system deserves a special attention with regard to its photodynamic antifungal activity against antibiotic-resistant strains and the results sound promising with zones of inhibition around $55 \mathrm{~mm}$. The MIC against two strains was determined to be $2.5 \mu \mathrm{g} / \mathrm{ml}$ in PDT and the system is non-toxic upto $200 \mu \mathrm{g} / \mathrm{ml}$. The result is an assurance of the system to be developed into a multitasking drug delivery system with far reaching potentials.

Acknowledgments The first author thanks University Grants Commission for Senior Research Fellowship (Sr. No2061410045 Ref. No-22/06/2014 (i) EU-V). 
Authors' contributions Both the authors contributed to the study conception and design. Synthesis and analyses were performed by the first author Sherin Philip. The first draft of the manuscript was prepared by the first author and commented and modified by the corresponding author Sunny Kuriakose. Both the authors read and approved the final manuscript.

Funding Current research was funded by University Grants Commission (India) under the Senior Research Fellowship scheme (Sr.No-2061410045 Ref. No-22/06/2014 (i) EU-V).

\section{Availability of data and materials Not applicable.}

\section{Declarations}

Conflict of interest The authors declare that they have no conflict of interest.

Ethics approval The authors declare that the study conducted meet all the ethical standards as specified by the journal and did not involve any animal/human research. The data and materials as well as software applications used in the study comply with field standards.

\section{References}

Ahmad H, Venugopal K, Bhat AH, Kavitha K, Remanan A, Rajagopal K, Srinivasan R, Manikandan E (2020) Enhanced biosynthesis synthesis of copper oxide nanoparticles (CuO-NPs) for their antifungal activity toxicity against major phyto-pathogens of apple orchards. Pharm Res 37:246. https://doi.org/10.1007/s11095-02002966-x

Blaney L (2007) Magnetite $\left(\mathrm{Fe}_{3} \mathrm{O}_{4}\right)$ : properties, synthesis, and applications. Lehigh Review 15-2007:33-81

Chen RJ, Zhang YG, Wang DW, Dai H (2001) Noncovalent sidewall functionalization of single-walled carbon nanotubes for protein immobilization. J Am Chem Soc 123:3838-3839

Chen SH, Duhamel J, Bahun GJ, Adronov A (2011) Quantifying the presence of unwanted fluorescent species in the study of pyrene labelled macromolecules. J Phys Chem B 115:9921-9929

Chourpa I, Douziech-Eyrolles L, Ngaboni-Okassa L, Fouquenet JF, Cohen-Jonathan S, Souce M, Marchais H, Dubois P (2005) Molecular composition of iron oxide nanoparticles, precursors for magnetic drug targeting, as characterized by confocal Raman microspectroscopy. Analyst 130:1395

Dandamudi S, Campbell RB (2007) The drug loading, cytotoxicty and tumor vascular targeting characteristics of magnetite in magnetic drug targeting. Biomaterials 28:4673

Das MI, Khan R, Jayabalan SK, Behera S, Yun SI, Tripathy SK, Mishra A (2016) Understanding the antifungal mechanism of Ag@ZnO core-shell nanocomposites against Candida krusei. Sci Rep 6:36403
Foote CS (1991) Definition of type I and type II photosensitized oxidation. Photochem Photobiol 54:659

Ghorbani J, Rahban D, AghamiriS TA, Bahador A (2018) Photosensitizers in antibacterial photodynamic therapy: an overview. Laser Ther 27:293-302

Huang L, Xuan Y, Koide Y, Zhiyentayev T, Tanaka M, Hamblin MR (2012) Type I and Type II mechanisms of antimicrobial photodynamic therapy: an in vitro study on gramnegative and gram-positive bacteria. Lasers Surg Med 44:490-499

Huang H (2017) Effect of intense pulsed light on Trichophyton rubrum growth in vitro. J Southern Med Univ 37:853-857

Jain TK, Morales MA, Sahoo SK, Leslie-Pelecky DL, Labhasetwar V (2005) Iron oxide nanoparticles for sustained delivery of anticancer agents. Mol Pharm 2:194

Kim K, Sung WS, Suh BK, Moon S, Choi J, Kim JG, Lee DG (2009) Antifungal activity and mode of action of silver nano-particles on Candida albicans. Biometals 22:235-242

Kohanski MA, Dwyer DJ, Hayete B, Lawrence CA, Collins JJ (2007) A common mechanism of cellular death induced by bactericidal antibiotics. Cell 130:797-810

Kumari M, Giri VP, Pandey S, Kumar M, Katiyar R, Nautiyal C, Mishra A (2019) An insight into the mechanism of antifungal activity of biogenic nanoparticles than their chemical counterparts. Pestic Biochem Physiol 157:45-52

Laurent S, Forge D, PortM RA, LE RobicC V, Muller RN (2008) Magnetic iron oxide nanoparticles: synthesis, stabilization, vectorization, physicochemical characterizations, and biological applications. Chem Rev 108:2064-2110

Neises B, Steglich W (1978) Simple method for the esterification of carboxylic acids. Angew Chem Int Ed Eng 17:522-524

Philip S, Kuriakose S (2017) Antibacterial activity of zero-valent iron nanoparticles synthesized by green protocols using Murraya koenigii extract. Eur J Biomed Pharm 4:630-633

Philip S, Kuriakose S (2019) Aggregation enhanced excimer emission supported, monomeric fluorescence quenching of dendritic hyperbranched polyglycerol coupled 1-pyrene butyric acid lumophore as a sensing probe for $\mathrm{Fe}_{2} \mathrm{O}_{3}$ nanoparticles. J Fluoresc 29:387-398

Philip S, Kuriakose S (2020) Synthesis, characterization and antimicrobial properties of superparamagnetic $\alpha-\mathrm{Fe}_{2} \mathrm{O}_{3}$ nanoparticles stabilized by biocompatible starch. J Clust Sci. https://doi.org/10.1007/s10876-020-01898-1

Rajan S, Nathan L, Kelly L, Catherine P (2016) Prospects in the application of photodynamic therapy in oral cancer and premalignant lesions. Cancers 8:83

Read AF, Woods RJ (2014) Antibiotic resistance management. Evol Med Public Health 1:147

Shah AH, Manikandan E, Ahamed MB, Mir DA, Mir SA (2014) Antibacterial and blue shift investigations in sol-gel synthesized CrxZn1-xO nanostructures. J Lumin 145:944-950. https://doi.org/10.1016/j.jlumin.2013.09. 023

Spellberg B, Gilbert DN (2014) The Future of antibiotics and resistance: a tribute to a career of leadership by John Bartlett. Clin Infect Dis 59(suppl 2):S71-S75

Ventola CL (2015) The antibiotic resistance crisis: part 1: causes and threats. Pharm Ther 40:277-283 
Viswanathan VK (2002) Off-label abuse of antibiotics by bacteria. Gut Microbes 5:3-4

Wang SS, Chen J, Keltner L, Christophersen J, Zheng F, Krouse M, Singhal A (2002) New technology for deep light distribution in tissue for phototherapy. Cancer J 8:154-163

Wheat LJ, Azar MM, Bahr NC, Spec A, Relich RF, Hage C (2016) Histoplasmosis. Infect Dis Clin North Am 30(1):207-227

Wright GD (2014) Something old, something new: revisiting natural products in antibiotic drug discovery. Can $\mathrm{J}$ Microbiol 60:147-154
Zaugg C, Monod M, Weber J, Harshman K, Pradervand S, Thomas J, Bueno M, Giddey K, Staib P (2009) Gene expression profiling in the human pathogenic dermatophyte Trichophyton rubrum during growth on proteins. Eukaryot Cell 8:241-250

Publisher's Note Springer Nature remains neutral with regard to jurisdictional claims in published maps and institutional affiliations. 